\title{
Adolescent blood pressure, body mass index and skin folds: sorting out the effects of early weight and length gains
}

\author{
Ana M B Menezes, ${ }^{1}$ Pedro C Hallal, ${ }^{1}$ Samuel C Dumith, ${ }^{1}$ Alicia M Matijasevich, ${ }^{1}$ \\ Cora L P Araújo, ${ }^{1}$ John Yudkin, ${ }^{2}$ Clive Osmond, ${ }^{3}$ Fernando C Barros, ${ }^{4}$ \\ Cesar G Victora ${ }^{1}$
}

'Postgraduate Program in Epidemiology, Federal University of Pelotas, Pelotas, Brazil International Health and Medical Education Center, University College London, London, UK

${ }^{3}$ Epidemiology Resource Center, University of Southampton, Southampton, UK

${ }^{4}$ Postgraduate Program in Health and Behavior, Catholic University of Pelotas, Pelotas, Brazi

\section{Correspondence to}

Dr Ana MB Menezes, Rua Marechal Deodoro 1160 96020-220, Pelotas, RS, Brazil; anamene@terra.com.br

Accepted 19 January 2011 Published Online First 15 February 2011

\section{ABSTRACT}

Background Although there is longstanding evidence of the short-term benefits of promoting rapid growth for young children in low-income settings, more recent studies suggest that early weight gain can also increase the risk of chronic diseases in adults. This paper attempts to separate the effects of early life weight and length/height gains on blood pressure, body mass index (BMI), sum of skin folds and subscapular/triceps skin fold ratio at $14-15$ years of age.

Methods The sample comprised 833 members of a prospective population-based birth cohort from Brazil. Conditional size (weight or height) analyses were used to express the difference between observed size at a given age and expected size based on a regression, including all previous measures of the same anthropometric index. A positive conditional weight or height indicates growing faster than expected given prior size.

Results Conditional weights at all age ranges were positively associated with most outcomes; each z-score of conditional weight at 4 years was associated with an increase of $6.1 \mathrm{~mm}$ in the sum of skin folds $195 \% \mathrm{Cl} 4.5$ to 7.6) in adolescence after adjustment for conditional length/height. Associations of the outcomes with conditional length/height were mostly negative or nonsignificant-each z-score was associated with a reduction of $2.4 \mathrm{~mm}(95 \% \mathrm{Cl}-3.8$ to -1.1$)$ in the sum of skin folds after adjustment for conditional weight. No associations were found with the skin fold ratio.

Conclusion The promotion of rapid length/height gain without excessive weight gain seems to be beneficial for long-term outcomes, but this requires confirmation from other studies.

\section{INTRODUCTION}

A wide body of evidence supports the short term benefits of promoting rapid weight gain for young children in low-income settings. ${ }^{1-3}$ However, recently, several authors suggest that early weight gain can also increase the risk of chronic diseases in adults. $^{4-6}$ Another in this debate is that rapid weight gain in poor populations is positively associated with human capital in adults-including schooling, economic productivity and next-generation birth weight. ${ }^{7} 8$ This has been described as the 'catch-up dilemma'.

The first studies on the long-term consequences of early life exposures suggested that birth weight was inversely associated with the risk of chronic diseases in adulthood, ${ }^{10}$ but it has been argued that such effect was primarily due to postnatal instead of prenatal weight trajectories. ${ }^{11}$ Further studies tried to establish whether there was a specific age range in which rapid weight gain was most strongly associated with beneficial ${ }^{8} 8$ or detrimental adult outcomes. ${ }^{12} 13$

Because weight gain in a given age range is not independent from previous weight gains, ${ }^{14-16}$ conditional analyses have been more recently proposed to overcome the lack of independence. ${ }^{14}$ Conditional size is defined as the amount by which the size at the end of a time interval exceeds that which would have been predicted at the beginning of the interval from previous measurements of the same anthropometric parameter-for example, weight or height. A positive conditional weight or height indicates growing faster than expected given prior size. An additional issue yet to be addressed is how to disentangle the long-term effects of early weight gain from those of length/height gain during the same age range during childhood.

We have used this novel approach to analyse data from a birth cohort study in Southern Brazil in order to explore the independent effects of weight and length/height gains during different periods in the first 4 years of life on blood pressure and on measures of obesity and central fat distribution at 14-15 years of age.

\section{METHODS}

Pelotas is a 340000 -inhabitant city located in the extreme south of Brazil near the border with Uruguay and Argentina. All hospital-born children in 1993 whose families were residents of the city $(\mathrm{N}=5265)$ were eligible for a birth cohort study; there were only 16 refusals. ${ }^{17} 18$ Low birth weight $(<2500 \mathrm{~g})$ children comprised $9.8 \%$ of the sample. All low birth weight children and a random 20\% sample of the remaining children $(\mathrm{N}=1454)$ were followed up at home at the ages of 6, 12 and 48 months, and all cohort participants were visited at the age of $14-15$ years. Analyses presented here are restricted to subjects located in these four waves of data collection and are weighted to represent the total population. Further details on the methodology of the 1993 Pelotas (Brazil) birth cohort study are available elsewhere. ${ }^{17} 18$

Birth weight was measured at the hospital by the study team using paediatric scales (Filizola, Sao Paulo, Brazil) with a precision of $10 \mathrm{~g}$, and birth length with a locally made infantometer with 
a precision of $1 \mathrm{~mm}$. Portable weighing scales were used to measure weight at home visits (PLENNA, São Paulo, Brazil). Length was measured at 6 and 12 months with the infantometer used for the birth measures and standing height was measured at 48 months. Measurements were converted into z-scores of weight for age (WAZ), length or height for age (HAZ) and body mass index (BMI; weight/height ${ }^{2}$ ) for age (BAZ) using the WHO Growth Standards. ${ }^{19}$

Outcome variables included systolic blood pressure, BMI, the sum of triceps and subscapular skin folds, and subscapular/ triceps ratios at $14-15$ years of age. Blood pressure was measured twice using a wrist digital Omron sphygmomanometer and the mean value was used in the analysis. A validation study using mercury sphygmomanometers as the gold standard showed that the quality of the measurements was adequate (mean difference $0.3 \mathrm{~mm} \mathrm{Hg}$ ). ${ }^{20}$ Participants were measured seated after a 10 min rest. We opted not to treat hypertension as a dichotomous outcome given its low prevalence at this age range. Skin folds were measured three times and the mean value used. The subscapular/triceps skin fold ratio was calculated by dividing the subscapular by the triceps skin fold measure and multiplying this ratio by 100 . Interviewers were trained and standardised on weight, height and skin folds measurements within the margins of error of the National Center for Health Statistics. ${ }^{21}$ Standardisation sessions were repeated every 2 months during fieldwork, which took place from January to July 2008 .

Confounding variables included child sex, child skin colour, family socioeconomic level (based on an assets index divided into quintiles), adolescent pubertal status (Tanner's stages), ${ }^{22}$ maternal pre-gestational BMI and maternal smoking during pregnancy. We used conditional weight and length/height variables to express the component of weight (or length/height) at a given age that is uncorrelated with earlier measures. ${ }^{14} 1523$ Conditional measures express how an individual child deviates from its own previous growth trajectory; thus, expressing acceleration or deceleration in growth. These were calculated as the residuals from linear regressions of weight (or length/height) at a given age on all prior weights (or lengths/heights). For example, a positive residual at 48 months indicates that a child grew more rapidly in the $12-48$ month age range than was predicted from his/her weight at birth, 6 and 12 months. Conditional size was expressed in z-scores using the local distribution. The main advantage of this approach is that-unlike traditional analyses - conditional weight or height at a given age is independent from earlier weights or heights. In describing the results, we used conditional weight at a given age (eg, 12 months) interchangeably with weight gain in the preceding age range (eg, 6-12 months) Nevertheless, all analyses were repeated using the unconditional or crude weight gains, expressed as z-score changes using the WHO standards. ${ }^{19}$

The analyses were based on four models. First, we report the unadjusted effect of the growth variables on adolescent outcomes. Second, we adjust these analyses for confounding variables measured in infancy and childhood. The third model includes further adjustments for potential mediating variables-adolescent BMI and height. In the last model, conditional weight was adjusted for conditional length/height at the same age and vice versa. Analyses were conducted in Stata version 10.0 and the significance level was set at 5\% for two-sided tests.

All phases of the 1993 Pelotas (Brazil) birth cohort study were approved by the Federal University of Pelotas Ethics Committee. Written informed consent from the parents or caretakers was obtained prior to each wave of data collection.

\section{RESULTS}

Follow-up rates at the 6 months and 1, 4 and 14-15 year followup visits of the 1993 Pelotas (Brazil) birth cohort were 96.8\%, $93.4 \%, 87.2 \%$, and $85.6 \%$, respectively. Full datasets were available for 833 adolescents. Subjects included in the analysis were similar to the rest of the cohort: $47.7 \%$ versus $49.7 \%$ were men and $20.3 \%$ versus $20.1 \%$ belonged to the poorest wealth quintile at birth. Outcome variables were also similar in the two groups (systolic blood pressure: 119.2 vs $119.4 \mathrm{~mm} \mathrm{Hg;} \mathrm{BMI:} 21.3$ vs $21.5 \mathrm{~kg} / \mathrm{m}^{2}$ ). Table 1 describes the sample in terms of covariates, infancy and childhood weight and length/height gain and adolescent outcomes.

Growth faltering was uncommon in the population under study. At the age of 4 years, $2.4 \%$ (according to WAZ) or $0.4 \%$ (according to BAZ) were underweight and $5.2 \%$ stunted (according to HAZ) compared to the WHO Child Growth Standards (below -2 SD relative to the median). ${ }^{19}$

Table 1 Descriptive statistics on infancy, childhood and adolescent variables

\begin{tabular}{|c|c|c|c|}
\hline Social, demographic and maternal variables & \multicolumn{2}{|l|}{$\mathbf{N}(\%)$} & $95 \% \mathrm{Cl}$ \\
\hline \multicolumn{4}{|l|}{ Sex } \\
\hline Boys & \multicolumn{2}{|c|}{$487(47.7)$} & 47.5 to 50.4 \\
\hline Girls & \multicolumn{2}{|c|}{$535(52.3)$} & 49.3 to 55.4 \\
\hline \multicolumn{4}{|l|}{ Skin colour } \\
\hline White & \multicolumn{2}{|c|}{$631(61.8)$} & 58.8 to 64.8 \\
\hline Black & \multicolumn{2}{|c|}{$195(19.1)$} & 16.7 to 21.5 \\
\hline Mixed & \multicolumn{2}{|c|}{$161(15.8)$} & 13.5 to 18.0 \\
\hline Others & \multicolumn{2}{|c|}{$34(3.3)$} & 2.2 to 4.4 \\
\hline \multicolumn{4}{|l|}{ Puberty status (Tanner stages) } \\
\hline $2-4$ & \multicolumn{2}{|c|}{$43(5.2)$} & 3.7 to 6.7 \\
\hline $5-7$ & \multicolumn{2}{|c|}{$392(47.0)$} & 43.7 to 50.5 \\
\hline $8-10$ & \multicolumn{2}{|c|}{$398(47.8)$} & 44.4 to 51.2 \\
\hline \multicolumn{4}{|l|}{ Family income at birth (quintiles) } \\
\hline 1 (poorest) & \multicolumn{2}{|c|}{$206(20.3)$} & 17.8 to 22.8 \\
\hline 2 & \multicolumn{2}{|c|}{$245(24.2)$} & 21.5 to 26.8 \\
\hline 3 & $189(1$ & & 16.2 to 21.0 \\
\hline 4 & $195(1$ & & 16.8 to 21.7 \\
\hline 5 (richest) & $179(1$ & & 15.3 to 20.0 \\
\hline Pre-gestational BMI $\left(\mathrm{kg} / \mathrm{m}^{2}\right)$ & & & \\
\hline$<18.5$ & $97(9$ & & 7.9 to 11.7 \\
\hline $18.5-24.9$ & 68316 & & 66.1 to 71.9 \\
\hline $25.0-29.9$ & $158(1$ & & 13.7 to 18.3 \\
\hline$\geq 30$ & $52(5$ & & 3.9 to 6.6 \\
\hline Smoking during pregnancy & & & \\
\hline No & 65516 & & 61.1 to 67.0 \\
\hline Yes & $367(3$ & & 33.0 to 38.9 \\
\hline Infancy and childhood anthropometry & $\mathbf{N}$ & Mean & SD \\
\hline Birth weight $(\mathrm{g})$ & 1022 & 2968 & 630 \\
\hline Weight gain (z-score) $0-6$ months & 1395 & 0.34 & 1.21 \\
\hline Weight gain (z-score) $6-12$ months & 1349 & 0.35 & 0.62 \\
\hline Weight gain (z-score) 12-48 months & 1238 & -0.12 & 0.95 \\
\hline Length/height gain (z-score) $0-6$ months & 1370 & 0.15 & 1.24 \\
\hline Length/height gain (z-score) 6-12 months & 1348 & 0.07 & 0.84 \\
\hline Length/height gain (z-score) 12-48 months & 1239 & 0.07 & 0.87 \\
\hline Adolescent measurements & $\mathbf{N}$ & Mean & SD \\
\hline BMl $\left(\mathrm{kg} / \mathrm{m}^{2}\right)$ & 1022 & 21.3 & 3.9 \\
\hline Systolic blood pressure (mm Hg) & 1022 & 119.2 & 9.8 \\
\hline Sum of triceps and subscapular skin folds (mm) & 1022 & 25.1 & 13.3 \\
\hline Subscapular/triceps ratio $\left(10^{2}\right)$ & 1022 & 87.0 & 26.5 \\
\hline Height $(\mathrm{cm})$ & 1022 & 161.9 & 8.6 \\
\hline
\end{tabular}

1993 Pelotas Birth Cohort, Brazil, 2008.

BMI, body mass index. 
Table 2 presents the correlation matrix for weight and length/ height gains. When expressed as z-scores, unconditional weight gain in a given age range tended to be inversely correlated to later weight gains; the same applied to length/height gain. Also, weight gain was positively correlated to length/height gain in the same age range. The use of conditional weights effectively removed the correlation between gains in successive periods with coefficients being equal to zero. Conditional weight in any period, and to a lesser extent conditional height, were associated with higher BMI at 14-15 years. For adolescent height, the associations with conditional weight were significant but weaker than those for conditional height.

Table 3 shows that early (0-6 months) and late (12-48 months) weight gains were positively associated with systolic blood pressure, whereas gains from 6-12 months were not. This was observed in the crude and confounder-adjusted analyses. Further adjustment for adolescent height and BMI must be interpreted with caution because these variables are likely part of the causal chain between early growth and adolescent outcomes. In these analyses, weight gain from 6-12 months became inversely associated with systolic blood pressure. Results were similar for diastolic pressure (data not shown). BMI and the sum of skin folds were positively associated with weight gain in all periods; the only exception is the lack of correlation with the sum of skin folds when potential mediating variables (adolescent BMI and height) are adjusted for. There were no significant associations with the skin fold ratio outcome in the adjusted models.

Results for length/height gain (table 4) show that, after adjustment for confounders, late gains tend to be associated with all outcomes except subscapular/triceps ratio but not early gains. Patterns were not clear-cut after adjustment for adolescent BMI and height, which suggest that these variables mediate the effect of childhood height gain on adolescent outcomes. There were not significant associations with the skin fold ratio in the adjusted models.

Table 5 repeats the confounder-adjusted analyses (model 1 in tables 3 and 4) with further adjustment of weight gain for length/height gain and vice versa. Weight gains in all periods tended to remain positively associated with all outcomes except for the skin fold ratio. In marked contrast to weight gain, associations between length gain and both obesity outcomes were mostly negative particularly for the body composition outcomes. Further adjustment for height at 14-15 years did not change the direction or significance of the associations (data not shown).

All the analyses described above were repeated using as explanatory variables the crude, or unconditional weight and height gains in each period, rather than conditional analyses. Although as expected the magnitude of the coefficients were different in the two sets of analyses, the findings were very similar in terms of direction and statistical significance (data not shown).

\section{DISCUSSION}

Our findings suggest that early weight gain increases adolescent blood pressure and fatness, whereas early length/height gains are not associated with higher blood pressure and seem to protect against overweight and fatness in adolescents. These results emerged when length/height gain and weight gain were adjusted for one another. The finding that the effects of weight and height gains seem to go in opposite directions is of great interest for public health.

Blood pressure is a challenging outcome for studies of the long-term consequences of early growth patterns because of its strong correlation with adult size. ${ }^{14} 24$ Using unconditional methods, previous studies reported that early weight gain was associated with higher blood pressure in adolescence and adulthood. ${ }^{25} 26$ In our length-adjusted analyses, putting on weight rapidly from $0-6$ months was associated with higher blood pressure in adolescence, whereas later weight gain was not. A previous analysis of five cohorts in low and middle-income countries found that conditional weight at 12 months was positively associated with adult mean blood pressure and pre-hypertension in the confounder-adjusted analyses, but the associations were no longer significant after adjustment for adult height. ${ }^{14}$

Table 2 Pearson correlation coefficients among infancy and childhood exposures and with BMI and height at 14-15 years

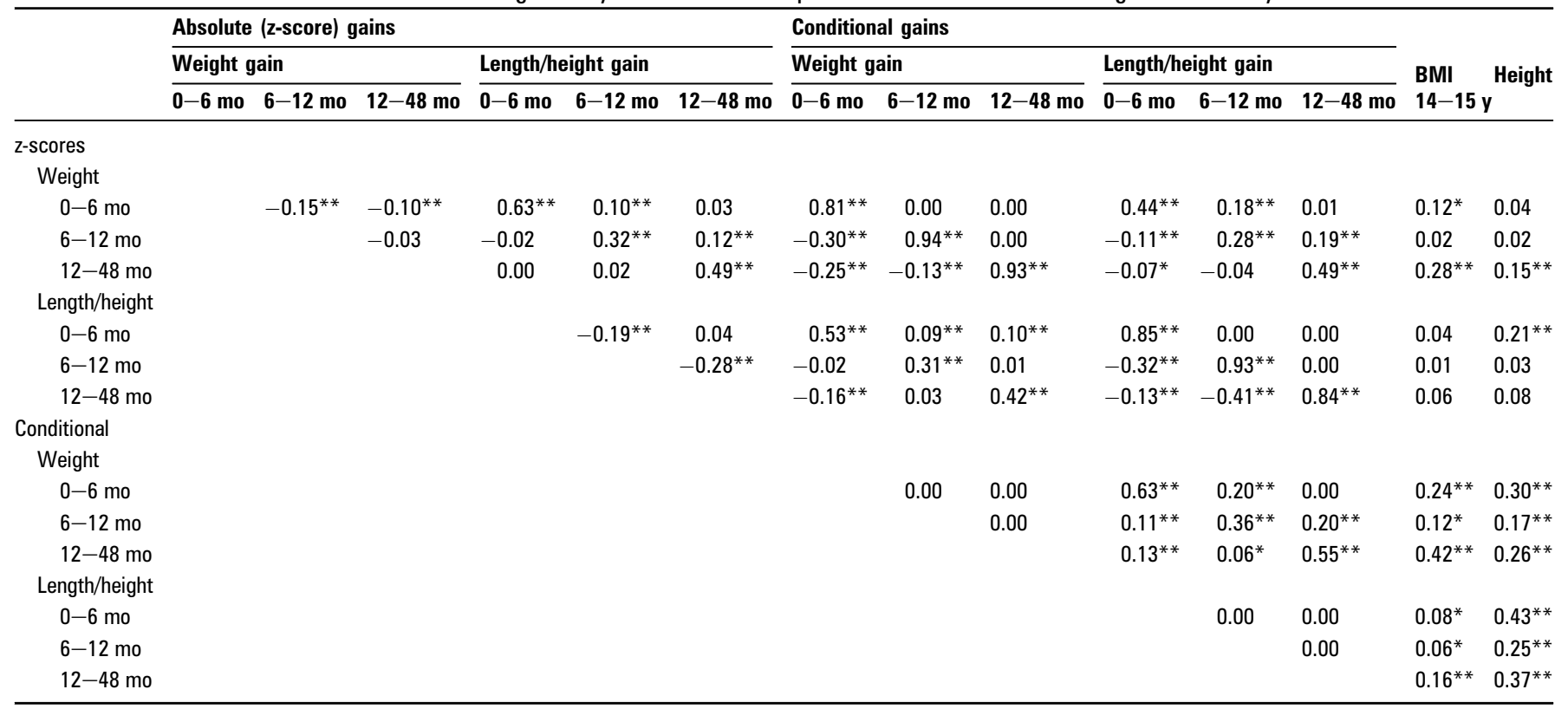


Table 3 Association between conditional weight gain in infancy and childhood and outcomes at age 14-15 years

\begin{tabular}{|c|c|c|c|c|c|c|c|c|c|}
\hline \multirow[b]{2}{*}{ Outcome } & \multicolumn{3}{|c|}{ Unadjusted } & \multicolumn{3}{|c|}{ Model 1* } & \multicolumn{3}{|c|}{ Model 2† } \\
\hline & $\beta \neq$ & SE & p Value & $\beta \neq$ & SE & p Value & $\beta \neq$ & SE & p Value \\
\hline \multicolumn{10}{|c|}{ Systolic blood pressure (mm Hg) } \\
\hline $6-12 \mathrm{mo}$ & -0.05 & 0.35 & 0.88 & -0.09 & 0.32 & 0.79 & -0.73 & 0.31 & 0.02 \\
\hline $12-48 \mathrm{mo}$ & 1.47 & 0.34 & $<0.01$ & 1.06 & 0.32 & $<0.01$ & -0.27 & 0.35 & 0.44 \\
\hline \multicolumn{10}{|l|}{ BMI $\left(\mathrm{kg} / \mathrm{m}^{2}\right)$} \\
\hline $12-48 \mathrm{mo}$ & 1.80 & 0.17 & $<0.01$ & 1.62 & 0.18 & $<0.01$ & 1.83 & 0.19 & $<0.01$ \\
\hline \multicolumn{10}{|c|}{ Sum of triceps and subscapular skin folds $(\mathrm{mm})$} \\
\hline $0-6 \mathrm{mo}$ & 2.72 & 0.43 & $<0.01$ & 2.86 & 0.47 & $<0.01$ & 0.11 & 0.28 & 0.70 \\
\hline $6-12 \mathrm{mo}$ & 1.61 & 0.53 & $<0.01$ & 1.56 & 0.56 & 0.01 & -0.07 & 0.29 & 0.80 \\
\hline $12-48 \mathrm{mo}$ & 4.83 & 0.57 & $<0.01$ & 4.35 & 0.62 & $<0.01$ & -0.19 & 0.40 & 0.63 \\
\hline \multicolumn{10}{|c|}{ Subscapular/triceps ratio ${ }^{*} 10^{2}$} \\
\hline
\end{tabular}

1993 Pelotas Birth Cohort, Brazil, 2008.

*Model 1: adjustment for sex, skin colour, puberty status, socioeconomic level, pre-gestational body mass index (BMI) and smoking during pregnancy.

†Model 2: adjustment for variables included in model 1 plus adolescent (14-15 years) BMI (except when the outcome was BMI) and height.

¥Change in outcome per SD increase in conditional weight or length/height.

$\beta$, beta coefficient; BMI, body mass index; mo, months.

Both BMI-which comprises fat and lean mass-and the sum of skin folds-which represents fat mass only-were positively associated with early weight gain. The regression coefficients suggest that weight gain from 12-48 months had a larger effect than earlier gains. It is reassuring that results on BMI and sum of skin folds are very consistent as these are two independent measures of obesity. A previous analysis of a subsample of 9 -year-olds from our cohort showed that while early weight gain was related to lean mass assessed through isotope dilution, later weight gain was associated with fat mass. ${ }^{27}$ Also using BMI and skin folds, Stettler and colleagues found that rapid weight gain during early infancy was associated with obesity in older children and young adults, ${ }^{12}$ and suggested that the first week of life was critical for BMI development. ${ }^{13}$ These studies did not report on the effects of height gain nor used conditional growth modelling.
Length gain from 0-6 months, when adjusted for weight gain in the same period, did not appear to increase blood pressure-if anything it was associated with a borderline reduction $(p=0.05)$ in systolic pressure. It was also associated with lower BMI and possibly with reduced skin folds. Length/height gains from 6-12 and 12-48 months were not associated with blood pressure, but showed negative associations with BMI and skin folds (not all of which were statistically significant), which suggest that putting on length/height without excessive weight gain is beneficial for body composition development.

Central deposition of fat can be measured both as waist circumference (alone or as a ratio to hip/thigh circumference) and as subscapular-to-triceps skin fold ratios. Both measures have been linked to glucose intolerance, hypertension and coronary heart disease. ${ }^{28-32}$ In our adjusted analyses, the skin fold ratio was not associated with early weight or height gains. This

Table 4 Association between conditional length/height gain in infancy and childhood and outcomes at age 14-15 years

\begin{tabular}{|c|c|c|c|c|c|c|c|c|c|}
\hline \multirow[b]{2}{*}{ Outcome } & \multicolumn{3}{|c|}{ Unadjusted } & \multicolumn{3}{|c|}{ Model 1* } & \multicolumn{3}{|c|}{ Model 2† } \\
\hline & $\beta \neq$ & SE & p Value & $\overline{\beta \neq}$ & SE & p Value & $\overline{\beta \neq}$ & SE & p Value \\
\hline \multicolumn{10}{|c|}{ Systolic blood pressure $(\mathrm{mm} \mathrm{Hg})$} \\
\hline $6-12 \mathrm{mo}$ & 0.39 & 0.34 & 0.26 & 0.35 & 0.32 & 0.28 & -0.33 & 0.35 & 0.34 \\
\hline $12-48 \mathrm{mo}$ & 1.61 & 0.38 & $<0.01$ & 1.23 & 0.37 & $<0.01$ & -0.13 & 0.45 & 0.78 \\
\hline \multicolumn{10}{|l|}{ BMI $\left(\mathrm{kg} / \mathrm{m}^{2}\right)$} \\
\hline $12-48 \mathrm{mo}$ & 0.73 & 0.16 & $<0.01$ & 0.75 & 0.18 & $<0.01$ & 0.93 & 0.20 & $<0.01$ \\
\hline \multicolumn{10}{|c|}{ Sum of triceps and subscapular skin folds (mm) } \\
\hline $0-6$ mo & 1.29 & 0.45 & $<0.01$ & 0.87 & 0.51 & 0.09 & 0.46 & 0.30 & 0.13 \\
\hline $6-12 \mathrm{mo}$ & 1.31 & 0.44 & $<0.01$ & 1.19 & 0.47 & 0.01 & 0.57 & 0.25 & 0.03 \\
\hline $12-48 \mathrm{mo}$ & 1.89 & 0.52 & $<0.01$ & 1.90 & 0.61 & $<0.01$ & -0.03 & 0.33 & 0.93 \\
\hline \multicolumn{10}{|c|}{ Subscapular/triciptal ratio*10 $10^{2}$} \\
\hline
\end{tabular}

1993 Pelotas Birth Cohort, Brazil, 2008.

* Model 1: adjustment for sex, skin colour, puberty status, socioeconomic level, pre-gestational BMI and smoking during pregnancy.

†Model 2: adjustment for variables included in model 1 plus BMI (except when the outcome was BMI) and height at 14-15 years.

$\neq$ Change in outcome per SD increase in conditional weight or length/height.

$\beta$, beta coefficient; BMI, body mass index; mo, months. 
Table 5 Associations between conditional weight and length/height gain in infancy and childhood adjusted for each other and outcomes at age $14-15$ years

\begin{tabular}{|c|c|c|c|c|c|c|}
\hline \multirow[b]{2}{*}{ Outcome } & \multicolumn{3}{|c|}{ Conditional weight gain* } & \multicolumn{3}{|c|}{$\begin{array}{l}\text { Conditional length/height } \\
\text { gain } \dagger\end{array}$} \\
\hline & $\overline{\beta \neq}$ & SE & p Value & $\overline{\beta \neq}$ & SE & p Value \\
\hline \multicolumn{7}{|c|}{ Systolic blood pressure $(\mathrm{mm} \mathrm{Hg})$} \\
\hline $0-6$ mo & 1.79 & 0.39 & $<0.01$ & -0.74 & 0.38 & 0.05 \\
\hline $6-12 \mathrm{mo}$ & -0.04 & 0.37 & 0.91 & 0.00 & 0.36 & 0.99 \\
\hline $12-48 \mathrm{mo}$ & 0.89 & 0.41 & 0.03 & 0.50 & 0.49 & 0.31 \\
\hline \multicolumn{7}{|l|}{ BMI $\left(\mathrm{kg} / \mathrm{m}^{2}\right)$} \\
\hline $0-6$ mo & 1.38 & 0.21 & $<0.01$ & -0.59 & 0.21 & 0.01 \\
\hline $6-12 \mathrm{mo}$ & 0.78 & 0.19 & $<0.01$ & -0.31 & 0.17 & 0.07 \\
\hline $12-48 \mathrm{mo}$ & 2.35 & 0.23 & $<0.01$ & -1.01 & 0.20 & $<0.01$ \\
\hline \multicolumn{7}{|c|}{ Sum of triceps and subscapular skin folds (mm) } \\
\hline $0-6$ mo & 3.46 & 0.60 & $<0.01$ & -1.07 & 0.63 & 0.09 \\
\hline $6-12 \mathrm{mo}$ & 1.72 & 0.62 & 0.01 & -0.13 & 0.52 & 0.80 \\
\hline $12-48 \mathrm{mo}$ & 6.06 & 0.79 & $<0.01$ & -2.44 & 0.67 & $<0.01$ \\
\hline \multicolumn{7}{|c|}{ Subscapular/triceps ratio ${ }^{*} 10^{2}$} \\
\hline $0-6 \mathrm{mo}$ & 0.05 & 1.24 & 0.97 & -1.73 & 1.35 & 0.20 \\
\hline $6-12 \mathrm{mo}$ & -0.04 & 1.12 & 0.97 & -1.55 & 1.18 & 0.19 \\
\hline $12-48 \mathrm{mo}$ & 0.73 & 1.24 & 0.56 & -0.54 & 1.51 & 0.72 \\
\hline
\end{tabular}

1993 Pelotas Birth Cohort, Brazil, 2008.

*Adjustment for sex, skin colour, puberty status, socioeconomic level, pre-gestational BMI, smoking during pregnancy and length/height gain in the same period.

†Adjustment for sex, skin colour, puberty status, socioeconomic level, pre-gestational BMI, smoking during pregnancy and weight gain in the same period.

$\neq$ Change in outcome per SD increase in conditional weight or length/height.

$\beta$, beta coefficient; BMl, body mass index; mo, months.

contradicts the findings of some studies, ${ }^{33} 34$ although there is no consensus on such observations. ${ }^{35}$ In some populations-for example in India-central fat deposition is already evident in infants. ${ }^{36}$

By adjusting early growth variables for adolescent BMI or height (model 2 in tables 3 and 4), we addressed the question of to what extent the effects of early weight and height gains on later outcomes may be channelled through adolescent size-which itself is partly a result of early growth patterns. For example, putting on weight rapidly in early life leads to larger BMI and height in adolescence, and early linear growth is also associated with adolescent height and to a lesser extent with adolescent BMI (table 2). In our view, the most important results from the public health perspective are those unadjusted for adolescent size (eg, model 1 in tables 3 and 4, and the models shown in table 5) because these address what might be expected from early interventions.

The present study is, to our knowledge, the first attempt to investigate long-term outcomes while mutually adjusting the effects of early weight and length/height gains. Also, by using the conditional method, we eliminated the correlation between growth variables in subsequent age ranges. ${ }^{15}{ }^{16} \mathrm{~A}$ limitation of our cohort is the lack of measurements at the critical age of 2 years, which is widely regarded at the upper limit of the window of opportunity for preventing undernutrition. ${ }^{7} 37$

In low and middle-income countries, paediatric practice has included promoting rapid weight gain to prevent undernutrition and its harmful consequences. ${ }^{38}$ This is highly justified in societies where undernutrition is responsible for a large proportion of the burden of disease, ${ }^{39}$ but in face of the nutrition transition there may be detrimental long-term consequences of rapid weight gain. ${ }^{7}$ Nevertheless, it has been proposed that in such societies, the benefits of rapid weight gain in the first 2 years regarding short-term morbidity and mortality outcomes, as well as long-term human capital outcomes, far outweigh its potential contribution to complex chronic diseases in adulthood. ${ }^{7}$

\section{What is already known on this subject?}

Although there is longstanding evidence of the short-term benefits of promoting rapid growth for young children in low-income settings, more recent studies suggest that early weight gain can also increase the risk of chronic diseases in adults. Supportive evidence on the benefits of rapid early weight gain in poor populations is provided by its positive association with human capital in adults. Rapid weight gain up to about the age of 2 years is more strongly associated with positive outcomes, whereas rapid weight gain in late childhood is associated with negative outcomes.

\section{What this study adds?}

Conditional weight gains in all different age ranges up to 4 years tended to be associated with higher blood pressure, BMl and skin folds. In marked contrast, rapid length/height gains tended to afford protection against most of these outcomes, particularly those related to body composition. These results emerged when length/height gain and weight gain were adjusted for one another.

Our findings suggest a new dimension to this debate, mainly that the promotion of rapid length/height gain without excessive weight gain may be beneficial for long-term outcomes. If our results are confirmed by other studies, it will be necessary to reassess the results of existing nutrition intervention studies to identify suitable strategies to achieve this growth pattern. Finally, our findings strongly support the need to monitor infant and child length/height in addition to the current practice of monitoring weight only. ${ }^{37}$

Acknowledgements This work was supported by the Wellcome Trust initiative: 'Major Awards for Latin America on Health Consequences of Population Change'. Earlier phases of the 1993 cohort study were funded by the European Union, the National Program for Centers of Excellence (Brazil), the National Research Council (Brazil) and the Ministry of Health (Brazil).

Funding The Wellcome Trust.

Competing interests None declared.

Ethics approval This study was conducted with the approval of the Federal University of Pelotas Ethics Committee (Brazill).

Provenance and peer review Not commissioned; externally peer reviewed.

\section{REFERENCES}

1. Chang SM, Walker SP, Grantham-McGregor S, et al. Early childhood stunting and later behaviour and school achievement. J Child Psychol Psychiatry 2002;43:775-83

2. Martorell R, Ho TJ. Malnutrition, morbidity and mortality. Population Devel Rev 1984:10:49-68.

3. Victora CG, Barros FC, Horta BL, et al. Short-term benefits of catch-up growth for small-for-gestational-age infants. Int J Epidemiol 2001;30:1325-30.

4. Singhal A, Lucas A. Early origins of cardiovascular disease: is there a unifying hypothesis? Lancet 2004;363:1642-5

5. Ong KK, Loos RJF. Rapid infancy weight gain and subsequent obesity: Systematic reviews and hopeful suggestions. Acta Paediatrica 2006;95:904-8.

6. Sachdev HS, Fall $\mathrm{CH}$, Osmond $\mathrm{C}$, et al. Anthropometric indicators of body composition in young adults: relation to size at birth and serial measurements of body mass index in childhood in the New Delhi birth cohort. Am J Clin Nutr 2005:82:456-66

7. Victora CG, Adair L, Fall C, et al. Maternal and child undernutrition: consequences for adult health and human capital. Lancet 2008;371:340-57. 
8. Hoddinott J, Maluccio JA, Behrman JR, et al. Effect of a nutrition intervention during early childhood on economic productivity in Guatemalan adults. Lancet 2008;371:411-16.

9. Victora CG, Barros FC. Commentary: the catch-up dilemma-relevance of Leitch's 'low-high' pig to child growth in developing countries. Int $\mathrm{J}$ Epidemiol 2001:30:217-20.

10. Barker DJ, Winter PD, Osmond C, et al. Weight in infancy and death from ischaemic heart disease. Lancet 1989;2:577-80.

11. Lucas A, Fewtrell MS, Cole TJ. Fetal origins of adult disease-the hypothesis revisited. BMJ 1999;319:245-9.

12. Stettler N, Kumanyika SK, Katz SH, et al. Rapid weight gain during infancy and obesity in young adulthood in a cohort of African Americans. Am J Clin Nutr 2003;77:1374-8.

13. Stettler N, Stallings VA, Troxel AB, et al. Weight gain in the first week of life and overweight in adulthood: a cohort study of European American subjects fed infant formula. Circulation 2005;111:1897-903.

14. Adair LS, Martorell $\mathrm{R}$, Stein $A D$, et al. Size at birth, weight gain in infancy and childhood, and adult blood pressure in 5 low- and middle-income-country cohorts: when does weight gain matter? Am J Clin Nutr 2009;89:1383-92.

15. Keijzer-Veen MG, Euser AM, van Montfoort N, et al. A regression model with unexplained residuals was preferred in the analysis of the fetal origins of adult diseases hypothesis. J Clin Epidemiol 2005;58:1320-4.

16. Tu YK, West R, Ellison GT, et al. Why evidence for the fetal origins of adult disease might be a statistical artifact: the "reversal paradox" for the relation between birth weight and blood pressure in later life. Am J Epidemiol 2005;161:27-32.

17. Victora CG, Hallal PC, Araujo CL, et al. Cohort profile: the 1993 Pelotas (Brazil) birth cohort study. Int J Epidemiol 2008;37:704-9

18. Victora CG, Araujo CL, Menezes AM, et al. Methodological aspects of the 1993 Pelotas (Brazil) Birth Cohort Study. Rev Saude Publica 2006;40:39-46.

19. WHO Multicentre Growth Reference Study Group. WHO Child Growth Standards based on length/height, weight and age. Acta Paediatr (Suppl) 2006; 450:76-85.

20. Menezes AM, Dumith SC, Noal RB, et al. Validity of a wrist digital monitor for blood pressure measurement in comparison to a mercury sphygmomanometer. Arq Bras Cardiol 2010;94:345-9, 65-70.

21. Cameron N. Reliability. In: Cameron Ne, ed. The Measurement of Human Growth London: Croom Helm, 1984:100-12.

22. Tanner JM. Normal growth and techniques of growth assessment. Clin Endocrinol Metab 1986:15:411-51.

23. Li H, Stein AD, Barnhart HX, et al. Associations between prenatal and postnatal growth and adult body size and composition. Am J Clin Nutr 2003;77:1498-505
24. Huxley RR, Shiell AW, Law CM. The role of size at birth and postnatal catch-up growth in determining systolic blood pressure: a systematic review of the literature. J Hypertens 2000;18:815-31.

25. Horta BL, Barros FC, Victora CG, et al. Early and late growth and blood pressure in adolescence. J Epidemiol Community Health 2003;57:226-30.

26. Law CM, Shiell AW, Newsome CA, et al. Fetal, infant, and childhood growth and adult blood pressure: a longitudinal study from birth to 22 years of age. Circulation 2002;105:1088-92

27. Wells JC, Hallal PC, Wright A, et al. Fetal, infant and childhood growth: relationships with body composition in Brazilian boys aged 9 years. Int $\mathrm{J}$ Obes (Lond) 2005;29:1192-8

28. Burchfiel CM, Shetterly SM, Baxter J, et al. The roles of insulin, obesity, and fat distribution in the elevation of cardiovascular risk factors in impaired glucose tolerance. The San Luis Valley Diabetes Study. Am J Epidemiol 1992:136:1101-9.

29. Kannel WB, Cupples LA, Ramaswami R, et al. Regional obesity and risk of cardiovascular disease; the Framingham Study. J Clin Epidemio 1991:44:183-90

30. Yusuf S, Hawken S, Ounpuu S, et al. Obesity and the risk of myocardial infarction in 27,000 participants from 52 countries: a case-control study. Lancet 2005;366:1640-9.

31. Snijder MB, Dekker JM, Visser M, et al. Trunk fat and leg fat have independent and opposite associations with fasting and postload glucose levels: the Hoorn study. Diabetes Care 2004:27:372-7.

32. Sosenko JM, Kato M, Soto R, et al. A comparison of adiposity measures for screening non-insulin dependent diabetes mellitus. Int J Obes Relat Metab Disord 1993:17:441-4.

33. Chomtho S, Wells JC, Williams JE, et al. Infant growth and later body composition: evidence from the 4-component model. Am J Clin Nutr 2008;87:1776-84.

34. Gonzalez DA, Nazmi A, Victora CG. Growth from birth to adulthood and abdominal obesity in a Brazilian birth cohort. Int J Obes (Lond) 2009;34:195-202.

35. Wells JC, Chomtho S, Fewtrell MS. Programming of body composition by early growth and nutrition. Proc Nutr Soc 2007;66:423-34.

36. Yajnik CS, Lubree HG, Rege SS, et al. Adiposity and hyperinsulinemia in Indians are present at birth. J Clin Endocrinol Metab 2002:87:5575-80.

37. Shrimpton R, Victora CG, de Onis M, et al. Worldwide timing of growth faltering: implications for nutritional interventions. Pediatrics 2001:107:E75.

38. Morley D, Woodland M. See How They Grow: Monitoring Child Growth forwith which to compare current status. Appropriate Health Care in Developing Countries. New York: Oxford University Press, 1979.

39. Black RE, Allen LH, Bhutta ZA, et al. Maternal and child undernutrition: global and regional exposures and health consequences. Lancet 2008;371:243-60.

\section{Online First}

Want the latest articles? Why not try Online First, which publishes articles three weeks after acceptance, months ahead of publication in a printed journal issue. To view these and all our online content, visit jech.bmj.com. 